\title{
Inspiratory muscle training for enhancing repeated-sprint ability: A pilot study
}

Ramón F. Rodriguez ${ }^{1}$, Robert J. Aughey ${ }^{1}$, François Billaut ${ }^{2} \&$ Nathan E. Townsend ${ }^{3}$

${ }^{1}$ Institute for Health and Sport, Victoria University, Melbourne, Australia.

2Department of Kinesiology, University Laval, Quebec, Canada.

${ }^{3}$ College of Health and Life Sciences, Hamad Bin Khalifa University, Doha, Qatar.

Corresponding Author:

ramon.rodriguez-anderson@vu.edu.au (RFR) 


\section{Abstract}

2 This pilot study examined the effect of inspiratory muscle training (IMT) on repeated-sprint ability and

3 vastus lateralis reoxygenation. Ten recreationally trained subjects were randomly divided into two groups to complete 4 weeks of IMT or Sham (placebo) training. Pre- and post-intervention, a repeatedsprint ability (RSA) test was performed in both normoxia and hypoxia $\left(\mathrm{F}_{\mathrm{i}} \mathrm{O}_{2} \approx 14.5 \%\right)$. Vastus lateralis reoxygenation $\left(\mathrm{VL}_{\text {reoxy }}\right)$, defined as peak to minimum amplitude deoxyhaemoglobin for each sprint/recovery cycle, was assessed during all trials using near-infrared spectroscopy. For total work performed, power analysis revealed that for small, medium and large effects (Cohen's $f$ ), sample sizes of $n=8,16$ and 90 respectively, are required to achieve a power of $80 \%$ at an a level of 0.05 . Maximal inspiratory mouth pressure increased in IMT by $36.5 \%, 95 \% \mathrm{Cl}[20.9,61.6]$ and by $2.7 \%, 95 \% \mathrm{Cl}[-4.46$,

11 8.8] in Sham. No clear difference in the change of work completed during the sprints between groups 12 were observed in normoxia (Sham $-0.805 \mathrm{~kJ}, 95 \% \mathrm{Cl}[-3.92,0.39]$; IMT $-2.06 \mathrm{~kJ}, 95 \% \mathrm{Cl}[-11.5,4.96]$; $13 P=0.802$ ), or hypoxia (Sham $-3.09 \mathrm{~kJ}, 95 \% \mathrm{Cl}[-7,0.396]$; IMT $0.354 \mathrm{~kJ}, 95 \% \mathrm{Cl}[-1.49,2.1]$; $P=0.802$ ).

$14 \mathrm{VL}_{\text {reoxy }}$ in IMT increased by $9.34 \%, 95 \% \mathrm{Cl}[5.15,13.7]$ in normoxia only. In conclusion, despite a large 15 increase in IMT, this was only associated with a small effect on RSA in our pilot study cohort. Owing to 16 a potentially relevant impact of training the inspiratory musculature, future studies should include a sample size of at least $16-20$ to detect moderate to large effects on RSA. 


\section{Introduction}

During whole-body moderate-intensity exercise, the oxygen cost of breathing contributes 3-6\% towards total pulmonary oxygen uptake $\left(\mathrm{VO}_{2}\right)$, which increases to $10-15 \%$ during high-intensity exercise [1]. Moreover, if a high work of breathing is sustained, respiratory muscle fatigue can develop, resulting in a reflex increase in muscle sympathetic nerve activity [2]. This response, known as the respiratory muscle metaboreflex, attenuates locomotor muscle blood flow in favour of the respiratory musculature, which hastens the development of locomotor skeletal muscle fatigue [3]. Moreover, exercise in hypoxia is associated with a higher ventilatory equivalent for oxygen and peripheral muscle fatigue [4]. Therefore, respiratory muscle training may represent an effective strategy to alleviate the detrimental effect of sustained high work of breathing during intense exercise, particularly under hypoxic conditions.

Inspiratory muscle training (IMT) has been associated with enhanced exercise performance during the Yo-Yo intermittent recovery test [5, 6], time-trials [7-9], constant load cycling [10, 11], and repeated-sprint exercise (RSE) [12]. By improving the functional capacity of the respiratory muscles, the relative intensity of breathing at a given ventilatory rate decreases. Reducing the relative intensity of hyperpnoea following IMT has been shown to blunt the respiratory muscle metaboreflex $[13,14]$, reduce the $\mathrm{O}_{2}$ cost of breathing [15], and lessen respiratory muscle fatigue in both normoxia and hypoxia [16]. The application of IMT as a method to enhance repeated-sprint ability (RSA) has only been tested in field-based protocols $[12,17]$, with no work to our knowledge in a controlled laboratory setting under hypoxic conditions.

The ability to maintain performance during RSE is underpinned by the capacity to deliver $\mathrm{O}_{2}$ to the locomotor muscles in the short rest periods between sprints [18]. Thus, when RSE is performed in hypoxia, this capacity is negatively impacted [19]. However, respiratory muscle oxygenation appears to be protected, potentially reflecting preferential blood flow redistribution to the respiratory muscles [20]. Interestingly, there is some indication that heightened respiratory muscle work has little consequence on locomotor muscle oxygenation during RSE performed in normoxia [21]. It is possible that when highintensity exercise is interspersed with rest periods, there is enough capacity in the cardiovascular system to maintain $\mathrm{O}_{2}$ supply to both the locomotor and respiratory muscle. Nevertheless, IMT has been shown to improve RSE in normoxic conditions [12], and thus, could also be beneficial for RSE in 


\section{$51 \quad$ Methods}

\section{Power and sample size estimation} hypoxia. familiarisation and the normoxia pre-intervention trials (Fig 1). measures". also assessed using at the $0.01,0.05$ and 0.1 level.

\section{Pilot study}

\section{Design}

respiratory musculature, the activation of the respiratory muscle metaboreflex may be delayed, thereby improving RSE [15]. We examined data from a previous investigation [20], and carried out a pilot study to determine the feasibility of IMT to induce an ergogenic effect on RSE performance in normoxia and

Power and sample size estimations were conducted using G*Power 3.1.9.6 [22]. Total work performed on the cycle ergometer was considered the primary outcome measure and was the focus of analysis. Calculations were based on a two-way analysis of variance (ANOVA) with two levels for group (control vs experimental), and two levels for time (Pre- vs Post-intervention). Nonsphericity correction $\varepsilon$ was set to 1, and the Pearson's moment correlation coefficient $(r)$ was determined from the second

Fig 1: Correlation between the total mechanical work completed during the second Familiarisation trial and the Baseline Normoxia trial. The black dots represent individual subjects ( $=9$ ), and the grey line represents the line of identity. A linear model was fit to the data represented by the blue line and $95 \% \mathrm{Cl}$ by the grey shaded area. Pearson's moment correlation coefficient $(r)$ was calculated and used in the sample size and power analysis as the "correlation among repeated

Power $(1-\beta)$ was calculated as a function of sample size $(n)$ and effect size (Cohen's $f$ ). Effect size thresholds were set at small, 0.01 ; medium, 0.25 ; large, 0.4 . The effect of $\alpha$ error probability was

Ten males accustomed to high-intensity activity were recruited to participate in this study (Sham: age $=24.8 \pm 2.4$ years, body mass $=77.0 \pm 10.3 \mathrm{~kg}$, height $=77.6 \pm 6.8 \mathrm{~m} ;$ IMT: age $=27.2 \pm$ 2.2 years, body mass $=80.2 \pm 9.3 \mathrm{~kg}$, height $=179.0 \pm 9.0 \mathrm{~m}$ ). Subjects self-reported to be healthy and with no known neurological, cardiovascular or respiratory diseases. After being fully informed of the requirements, benefits, and risks associated with participation, each subject gave written informed consent. Ethical approval for the study was obtained from the institutional Human Research Ethics Committee, and the study conformed to the declaration of Helsinki. 
Participants reported to the laboratory for RSE testing on four separate occasions, which included one session in normoxic $\left(20.78 \pm 0.17 \% \mathrm{O}_{2}\right)$ and normobaric hypoxia $\left(14.49 \pm 0.33 \% \mathrm{O}_{2}\right)$ conditions, both pre- and post-intervention (Altitude Training Systems, Pulford Air and Gas Pty Ltd, Australia). All exercise trials were single-blinded and performed in a counterbalanced order. Testing was conducted within a $23.92 \mathrm{~m}^{2}$ environmental chamber set to $21^{\circ} \mathrm{C}$ and $40 \%$ relative humidity (Heuch Pty Ltd, Australia). The training intervention commenced the following day after pre-testing. Post-testing began two days following the intervention period and was completed within 48-72 hours.

\section{Inspiratory muscle training}

Subjects were randomly assigned to 4 weeks of either Inspiratory Muscle Training (IMT) or Sham training using a POWERbreathe ${ }^{\circledR}$ pressure threshold device (POWERbreathe ${ }^{\circ}$, HaB International Ltd, UK). Subjects were naïve that a Sham training group existed, but were informed that the study was investigating the effects of strength (IMT) vs. endurance (Sham) respiratory muscle training. The IMT group completed 30 inspiratory efforts at a pressure threshold starting at $50 \%$ of maximal inspiratory (mouth) pressure (MIP), twice per day (AM and PM), every day for 4 weeks. This protocol has been shown to elicit significant improvements in MIP $[9,10,12,15]$. Once participants could complete 30 breaths comfortably, they were instructed to increase the pressure threshold. The Sham group completed one session per day of 60 breaths at a pressure threshold corresponding to $15 \%$ MIP, every day for 4 weeks. The pressure threshold remained at $15 \%$ MIP for the entire intervention period, which has been shown to elicit no significant change in MIP [9, 12]. Subjects visited the laboratory weekly for training monitoring and inspiratory muscle strength assessment. A handheld respiratory pressure meter was used (MicroRPM, Micro Medical, Hoechberg, Germany) to measure MIP [23]. Pre-intervention, MIP was assessed to be $133 \pm 25 \mathrm{cmH}_{2} \mathrm{O}$ and $116 \pm 41 \mathrm{cmH}_{2} \mathrm{O}$ in the Sham and IMT groups respectively.

\section{Repeated-sprint exercise}

Testing was performed on an electromagnetically-braked cycle ergometer (Excalibur, Lode, Groningen, The Netherlands), in isokinetic mode (120 RPM). Subjects completed a 7 min warm-up consisting of 5 min of unloaded cycling at 60-70 RPM and two $4 \mathrm{~s}$ maximal effort sprints separated by 1 min each, then rested for another 2.5 min before commencing the repeated-sprint protocol. The RSE protocol included ten maximal sprint efforts lasting $10 \mathrm{~s}$ each, separated by 30 passive rest [20]. 
Therefore, each sprint/recovery duty cycle was $40 \mathrm{~s}$ in total. Before the experimental sessions, participants completed two familiarisation trials within one week of commencing the study.

\section{Near-infrared spectroscopy}

Locomotor muscle oxygenation was measured using NIRS (Oxymon MKIII, Artinis, The Netherlands). The optical sensor was fixed over the distal part of the vastus lateralis muscle belly approximately $15 \mathrm{~cm}$ above the proximal border of the patella. Source-detector optode spacing was set to $4.5 \mathrm{~cm}$, and a differential pathlength factor of 4.95 was used [20]. Data were acquired at $10 \mathrm{~Hz}$. A $10^{\text {th }}$ order zero-lag low-pass Butterworth filter was applied to the data to remove movement artefact and signal oscillation due to pedalling [24]. The filtered signal was used for all data analysis thereafter. Vastus lateralis deoxyhaemoglobin $\left(\mathrm{HHb}_{\mathrm{VL}}\right)$ was normalised to femoral artery occlusion so that $0 \%$ represented a $5 \mathrm{~s}$ average immediately prior the occlusion and $100 \%$ represented the maximum $5 \mathrm{~s}$ average. Arterial occlusion was achieved by placing a cuff around the root of the thigh, which was inflated to $300-350 \mathrm{mmHg}$ until $\mathrm{HHb}_{\mathrm{VL}}$ plateaued (3-7 min). Peaks and nadirs were identified for each $40 \mathrm{~s}$ sprint recovery period, and $\mathrm{VL}_{\text {reoxy }}$ was calculated as the difference between the peak to nadir of the $\mathrm{HHb}_{\mathrm{VL}}$ signal.

\section{Statistical analysis}

All data were analysed in the $\mathrm{R}$ environment using the estimation statistics framework with the dabest package [25], and in addition, repeated measures ANOVA's were performed on the mechanical work data with the stats [26] and sjstats [27] packages. Maximal inspiratory pressure (MIP), total mechanical work and average $\mathrm{VL}_{\text {reoxy }}$ are presented as raw data and effect size (mean difference) with bootstrap 95\% confidence interval $(95 \% \mathrm{Cl})$ statistics in Cumming estimation plots. Total work completed and $\mathrm{VL}_{\text {reoxy }}$ for each $40 \mathrm{~s}$ duty cycle, are presented as raw data with mean \pm standard deviation.

\section{Results}

\section{Power and sample size estimation}

Adopting the conventionally accepted power of $80 \%$ and a $5 \%$ a error probability (Fig 2 B), the estimated total sample size to detect a small (0.01), medium (0.25), and large (0.4) effect size for total work is 90,16 and 8 , respectively. 
Table 1: Analysis of variance results for total work performed in normoxia.

\begin{tabular}{lccccccccc}
\hline & df & SS & MS & $\begin{array}{c}\mathbf{F} \\
\text { value }\end{array}$ & $\begin{array}{c}\boldsymbol{P} \\
\text { value }\end{array}$ & $\mathbf{\eta}_{\mathbf{p}}{ }^{2}$ & $\boldsymbol{\omega}_{\mathbf{p}}{ }^{2}$ & $\begin{array}{c}\text { Cohen's } \\
\boldsymbol{f}\end{array}$ & Power \\
\hline $\begin{array}{l}\text { Training } \\
\text { (IMT vs. Sham) }\end{array}$ & 1 & 35.71 & 35.71 & 0.241 & 0.637 & 0.132 & 0.011 & 0.39 & 0.193 \\
$\begin{array}{l}\text { Time } \\
\text { (Pre vs. Post) }\end{array}$ & 1 & 10.27 & 10.27 & 0.351 & 0.57 & 0.042 & -0.034 & 0.209 & 0.09 \\
$\begin{array}{l}\text { Interaction } \\
\text { (Training vs. Time) }\end{array}$ & 1 & 1.97 & 1.97 & 0.067 & 0.802 & 0.008 & -0.049 & 0.092 & 0.058 \\
Residuals & 8 & 234.319 & 29.29 & & & & & &
\end{tabular}

Fig 2: Power as a function of sample size and effect size. Sample size was calculated based on performing an ANOVA: repeated-measures, within-between interaction effects. Nonsphericity correction $\varepsilon$ was set to 1 , and the correlation among repeated measures was set to 0.78 , the number of groups was 2 and number of measurements was 2. Calculations were based on a levels of 0.01 (panel A), 0.05 (panel B), and 0.1 (panel C)

\section{Pilot Study}

After four weeks of training, all participants in the IMP group increased their MIP, which represented a $36.5 \%, 95 \%$ [Cl $20.9 ; 61.6]$ increase, whereas it remains mostly constant on Sham $(2.7 \%$, 95\% Cl [-4.46, 8.8]). Group mean differences and individual changes are changes are presented in Fig 3.

Fig 3: Paired mean difference of the relative change from pre-intervention for maximal inspiratory pressure over the four weeks training period are shown in the above Cumming estimation plot. The raw data is plotted on the upper axes (panels $A$ and $C$ ); each mean difference is plotted on the lower axes as a bootstrap sampling distribution (panels $B$ and $D$ ). Mean differences are depicted as dots; $95 \%$ confidence intervals are indicated by the ends of the vertical error bars.

Outcomes from the ANOVA's are presented in Table 1 and Table 2. Total work completed and $\mathrm{VL}_{\text {reoxy }}$ for each trial is presented in Fig 4. There were no clear changes in total work for either normoxia (Sham -0.805 kJ, 95\% Cl [-3.92, 0.39]; IMT -2.06 kJ, 95\% Cl [-11.5, 4.96]), or hypoxia (Sham -3.09 kJ, $95 \% \mathrm{Cl}[-7,0.396] ;$ IMT $0.354 \mathrm{~kJ}, 95 \% \mathrm{Cl}[-1.49,2.1])$.

Abbreviations: Degrees of freedom, df; Sum of squares, SS; Mean sum of squares, MS; Partial eta-squared, $\eta p^{2}$; partial omega-squared, $\omega p^{2}$. 
Table 2: Analysis of variance (ANOVA) results for total work (kJ) performed in hypoxia.

\begin{tabular}{|c|c|c|c|c|c|c|c|c|c|}
\hline & df & SS & MS & $\begin{array}{c}F \\
\text { Value }\end{array}$ & $\begin{array}{c}P \\
\text { Value }\end{array}$ & $\eta_{p}^{2}$ & $\omega_{p}^{2}$ & $\begin{array}{c}\text { Cohen's } \\
f\end{array}$ & Power \\
\hline $\begin{array}{l}\text { Training } \\
\text { (IMT vs. Sham) }\end{array}$ & 1 & 202.82 & 202.82 & 1.26 & 0.294 & 0.782 & 0.124 & 0.581 & 1.895 \\
\hline $\begin{array}{l}\text { Time } \\
\text { (Pre vs. Post) }\end{array}$ & 1 & 9.37 & 9.37 & 1.327 & 0.283 & 0.142 & 0.001 & 0.016 & 0.407 \\
\hline $\begin{array}{l}\text { Interaction } \\
\text { (Training vs. Time) }\end{array}$ & 1 & 14.84 & 14.84 & 2.102 & 0.185 & 0.208 & 0.005 & 0.052 & 0.513 \\
\hline Residuals & 8 & 56.50 & 7.06 & & & & & & \\
\hline
\end{tabular}

Abbreviations: Degrees of freedom, df; Sum of squares, SS; Mean sum of squares, MS; Partial etasquared, $\eta p^{2} ;$ partial omega-squared, $\omega_{p}^{2}$.

Fig 4: Paired mean difference for 4 comparisons of total mechanical work and $\mathrm{VL}_{\text {reoxy }}$ is shown in the above Cumming estimation plot. Raw total work data is plotted in panel $A$, and the mean difference in panel $B$. Raw $\mathrm{VL}_{\text {reoxy }}$ is plotted in panel $\mathrm{C}$, and the mean difference in panel $\mathrm{D}$. Mean differences are depicted as dots; $95 \%$ confidence intervals are indicated by the ends of the vertical error bars.

\section{Discussion}

The primary objective of this pilot study was to assess the feasibility of using IMT as a tool for enhancing RSA and improving locomotor muscle tissue oxygenation. Based on the power analysis and sample size estimation of total work, we estimated a sample size between 8 to 90 participants would be required to detect large and small effects, respectively. Considering our sample size of $n=10$ (two groups of 5), we should have been able to detect a change in total work if the true effect size was at least large, well beyond the effect sizes (Choen's $f$ ) observed in the present study of 0.092 and 0.052 Table 1 and Table 2). Given that trained individuals are already well adapted to the demands of highintensity exercise, it may be that IMT only yields small to moderate effects on performance. Recruiting 90 participants for a training study is not feasible for many exercise science research programs; thus we suggest a total sample size of 16 to 20 participants (two groups of 8 to 10) to provide appropriate statistical power if the effects of IMT on RSE performance is at least moderate.

In the present study, we did not observe any clear performance benefit of IMT in either normoxic or hypoxic conditions (Fig 4). Meta-analysis has demonstrated positive performance benefits of respiratory muscle training (IMT, expiratory muscle training, and both methods combined) for constantload tests, time-trials and intermittent incremental tests (Yo-Yo intermittent recovery test) [28]. Moreover, linear regression models revealed that test duration also has an important mediating effect 
bioRxiv preprint doi: https//doi.org/10.1101/2021.01.22.427755; this version posted January 22, 2021. The copyright holder for this preprint (which was not certified by peer review) is the author/funder, who has granted bioRxiv a license to display the preprint in perpetuity. It is made available under aCC-BY 4.0 International license.

181

182

183

184

185

186

187

188

189

190

191

192

on the ergogenic impact of respiratory muscle training. It was estimated that for every minute of exercise, respiratory muscle training provides a $0.4 \%(95 \% \mathrm{Cl}[0.1,0.6 \%])$ performance improvement. Considering our RSE protocol lasts 6 min $10 \mathrm{~s}$, the maximal benefit that we can hope to detect would be $2.5 \%(95 \% \mathrm{Cl}[0.62,3.7 \%])$. However, there was only $1 \mathrm{~min} 40 \mathrm{~s}$ of actual exercise in our RSE protocol (ten $10 \mathrm{~s}$ sprints), and therefore we may only expect a performance benefit of $0.6 \%(95 \% \mathrm{Cl}$ $[0.2,1 \%])$. The true effect size may lie somewhere in the middle. Moreover, $85 \%$ of maximal oxygen uptake $\left(\mathrm{VO}_{2 \max }\right)$ appears to be the threshold for exercise intensity at which diaphragm fatigue develops [29], and therefore activation of the respiratory muscle metaboreflex [3]. In our previous work [21], we demonstrated that $\mathrm{VO}_{2}$ fluctuates between $90 \%$ and $70 \%$ of $\mathrm{VO}_{2 \max }$ during the sprint and recovery phases, respectively. The time spent above $85 \% \mathrm{VO}_{2 \max }$ may not have been sufficient for diaphragm fatigue to develop, and the possible ergogenic effect of IMT to manifest. Prehapse utilising a longer protocol, or one with shorter rest periods relative to the sprint, the benefits of IMT may be more obvious.

We observed a $36.5 \%$ increase in inspiratory muscle strength after the 4-week training intervention (Fig 3 ) which was similar in magnitude to previous studies $[9,12,15]$. Studies of IMT lasting beyond 4 weeks appear to show diminishing effectiveness over time. For example, over an 11-week training period, MIP has been demonstrated to increase by $41 \%$ in 4 weeks, and by an additional $4 \%$ in the remaining 7 weeks [9]. Previous studies that used a 6-week training intervention demonstrated reduced oxygen cost of hyperpnoea [15]. These results demonstrate that there is a point of diminishing returns of IMT beyond 4 weeks and that extending our training intervention (e.g. to 6 weeks) is unlikely to have yielded different results to what we obtained.

We previously reported that respiratory muscle oxygenation is maintained in hypoxia while $\mathrm{VL}_{\text {reoxy }}$ is compromised during RSE [20]. We therefore hypothesised that respiratory muscle training could be of potential ergogenic benefit for RSE is hypoxia, as it may reduce the oxygen cost of exercise hyperpnoea, and enhance locomotor muscle oxygen delivery [15, 20]. However, there was no apparent difference in $\mathrm{VL}_{\text {reoxy }}$ between the training groups (Fig $4 \mathrm{D}$ ). Therefore, it may be that respiratory muscle work (oxygen utilisation) has little effect on locomotor muscle oxygenation in RSE. Previously we have demonstrated that despite an increased inspiratory muscle force development, intercostal muscle tissue oxygenation (ration of oxyhaemoglobin to total haemoglobin) can be maintained relative to breathing 

competition between the locomotor and respiratory muscles for available oxygen supply.

\section{Conclusion}

These pilot data showed that IMT readily increases the strength of the inspiratory muscles;

213 however, no effect on RSA was found. Based on our sample size calculations, we estimate that we only 214 had the sensitivity to detect a large effect at $80 \%$ statistical power. Moreover, to detect medium and 215 small effects, at least 16 and 90 subjects would need to be recruited, respectively. Based on the 216 resources of exercise science laboratories, recruiting 90 subjects may not be feasible. Therefore, we 217 recommend a total sample size of $16-20$ is recruited for at least moderate effect sizes to be detected, 218 thus minimising the chances of type II error. Lastly, a double baseline should be utilised to establish the 219 smallest worthwhile change for which the magnitude to the training effect can be judged against.

\section{Acknowledgments}

We would like to thank Mario Popovic for his assistance during data collection. We would also like to thank the laboratory technical staff, Samantha Cassar, Jessica Meilak, and Collene Steward. Funding was provided by the Office for Researcher Training, Quality \& Integrity (PhD Student Budget) at Victoria University. The funder had no role in study design, data collection and analysis, decision to publish, or preparation of the manuscript.

\section{References}

227 1. Harms CA, Wetter TJ, McClaran SR, Pegelow DF, Nickele GA, Nelson WB, et al. Effects of 228 respiratory muscle work on cardiac output and its distribution during maximal exercise. Journal of 229 Applied Physiology. 1998;85(2):609-18. Epub 1998/08/04. doi: 10.1152/jappl.1998.85.2.609.

2302 2. St Croix CM, Morgan BJ, Wetter TJ, Dempsey JA. Fatiguing inspiratory muscle work causes 231 reflex sympathetic activation in humans. The Journal of Physiology. 2000;529(2):493-504. doi: 
233 3. Dempsey JA, Romer L, Rodman J, Miller J, Smith C. Consequences of exercise-induced

234 respiratory muscle work. Respiratory Physiology and Neurobiology. 2006;151(2-3):242-50. Epub 235 2006/04/18. doi: 10.1016/j.resp.2005.12.015.

236 4. Amann M, Pegelow DF, Jacques AJ, Dempsey JA. Inspiratory muscle work in acute hypoxia 237 influences locomotor muscle fatigue and exercise performance of healthy humans. American Journal 238 of Physiology - Regulatory, Integrative and Comparative Physiology. 2007;293(5):R2036-45. Epub 239 2007/08/24. doi: 10.1152/ajpregu.00442.2007.

240 5. Lomax M, Grant I, Corbett J. Inspiratory muscle warm-up and inspiratory muscle training: 241 separate and combined effects on intermittent running to exhaustion. Journal of Sports Sciences. 2011;29(6):563-9. Epub 2011/02/25. doi: 10.1080/02640414.2010.543911.

6. Nicks CR, Morgan DW, Fuller DK, Caputo JL. The influence of respiratory muscle training upon 244 intermittent exercise performance. International Journal of Sports Medicine. 2009;30(1):16-21. Epub 2008/11/01. doi: 10.1055/s-2008-1038794.

7. Salazar-Martínez E, Gatterer H, Burtscher M, Naranjo Orellana J, Santalla A. Influence of inspiratory muscle training on ventilatory efficiency and cycling performance in normoxia and hypoxia. Frontiers in Physiology. 2017;8(133):133. Epub 2017/03/25. doi: 10.3389/fphys.2017.00133.

8. Romer LM, McConnell AK, Jones DA. Inspiratory muscle fatigue in trained cyclists: effects of inspiratory muscle training. Medicine and Science in Sports and Exercise. 2002;34(5):785-92. Epub 2002/05/02. doi: 10.1097/00005768-200205000-00010.

9. Volianitis S, McConnell AK, Koutedakis $\mathrm{Y}$, McNaughton L, Backx K, Jones DA. Inspiratory muscle training improves rowing performance. Medicine and Science in Sports and Exercise. 2001;33(5):803-9. Epub 2001/04/27. doi: 10.1097/00005768-200105000-00020. training enhances pulmonary $\mathrm{O} 2$ uptake kinetics and high-intensity exercise tolerance in humans. Journal of Applied Physiology. 2010;109(2):457-68. 
259 11. Mickleborough TD, Nichols T, Lindley MR, Chatham K, lonescu AA. Inspiratory flow resistive

260 loading improves respiratory muscle function and endurance capacity in recreational runners.

261 Scandinavian Journal of Medicine and Science in Sports. 2010;20(3):458-68. Epub 2009/06/30. doi: 10.1111/j.1600-0838.2009.00951.x.

12. Romer LM, McConnell AK, Jones DA. Effects of inspiratory muscle training upon recovery time during high intensity, repetitive sprint activity. International Journal of Sports Medicine. 2002;23(5):35360. Epub 2002/08/08. doi: 10.1055/s-2002-33143. attenuates the human respiratory muscle metaboreflex. The Journal of Physiology. 2007;584(3):101928. doi: 10.1113/jphysiol.2007.140855.

14. McConnell AK, Lomax M. The influence of inspiratory muscle work history and specific inspiratory muscle training upon human limb muscle fatigue. The Journal of Physiology. 2006;577(Pt 1):445-57. doi: 10.1113/jphysiol.2006.117614.

15. Turner LA, Tecklenburg-Lund SL, Chapman RF, Stager JM, Wilhite DP, Mickleborough TD. Inspiratory muscle training lowers the oxygen cost of voluntary hyperpnea. Journal of Applied Physiology. 2012;112(1):127-34. Epub 2011/10/08. doi: 10.1152/japplphysiol.00954.2011. inspiratory muscle training on exercise responses in normoxia and hypoxia. Respiratory Physiology and Neurobiology. 2007;156(2):137-46. Epub 2006/09/26. doi: 10.1016/j.resp.2006.08.006. inspiratory muscle training in professional women football players: a randomized sham-controlled trial.

280 Journal of Sports Sciences. 2018;36(7):771-80. Epub 2017/06/18. doi: 10.1080/02640414.2017.1340659. 

limited O2 availability. Scandinavian Journal of Medicine and Science in Sports. 2013;23(3):185-93. Epub 2013/02/01. doi: 10.1111/sms.12052.

20. Rodriguez RF, Townsend NE, Aughey RJ, Billaut F. Respiratory muscle oxygenation is not impacted by hypoxia during repeated-sprint exercise. Respiratory Physiology and Neurobiology. 2019;260:114-21. Epub 2018/11/20. doi: org/10.1016/j.resp.2018.11.006.

21. Rodriguez RF, Townsend NE, Aughey RJ, Billaut F. Muscle oxygenation maintained during repeated-sprints despite inspiratory muscle loading. PLOS ONE. 2019;14(9):e0222487. Epub 2019/09/20. doi: 10.1371/journal.pone.0222487.

22. Faul F, Erdfelder E, Lang A-G, Buchner A. G*Power 3: A flexible statistical power analysis program for the social, behavioral, and biomedical sciences. Behavior Research Methods. 2007;39(2):175-91. Epub 2007/08/19. doi: 10.3758/BF03193146.

23. American Thoracic Society/European Respiratory Society. ATS/ERS Statement on respiratory muscle testing. American Journal of Respiratory and Critical Care Medicine. 2002;166(4):518-624. Epub 2002/08/21. doi: 10.1164/rccm.166.4.518.

24. Rodriguez RF, Townsend NE, Aughey RJ, Billaut F. Influence of averaging method on muscle deoxygenation interpretation during repeated-sprint exercise. Scandinavian Journal of Medicine and Science in Sports. 2018;28(11):2263-71. Epub 2018/06/09. doi: 10.1111/sms.13238. with estimation graphics. Nature Methods. 2019;16(7):565-6. Epub 2019/06/21. doi: 10.1038/s41592019-0470-3.

26. R Core Team. R: A language and environment for statistical computing. 3.6.3 ed. Vienna, Austria: R Foundation for Statistical Computing; 2020.

308 27. Daniel L. Statistical Functions for Regression Models. 0.17.9 ed: Zenodo; 2020. 
311 2012;42(8):707-24. Epub 2012/07/07. doi: 10.2165/11631670-000000000-00000. PubMed PMID:

31222765281

313 29. Johnson BD, Babcock MA, Suman OE, Dempsey JA. Exercise-induced diaphragmatic fatigue

314 in healthy humans. The Journal of Physiology. 1993;460(1):385-405. doi:

315 10.1113/jphysiol.1993.sp019477. 


\section{$r=0.78[95 \% \mathrm{Cl} 0.25,0.95]$}

80 -

bioRxiv preprint doi: https://doi.org/10.1101/2021.01.22.427755; this version posted January 22, 2021. The copyright holder for this preprint (which was not certified by peer review) is the author/funder, who has granted bioRxiv a license to display the preprint in

$75-$

$70-$

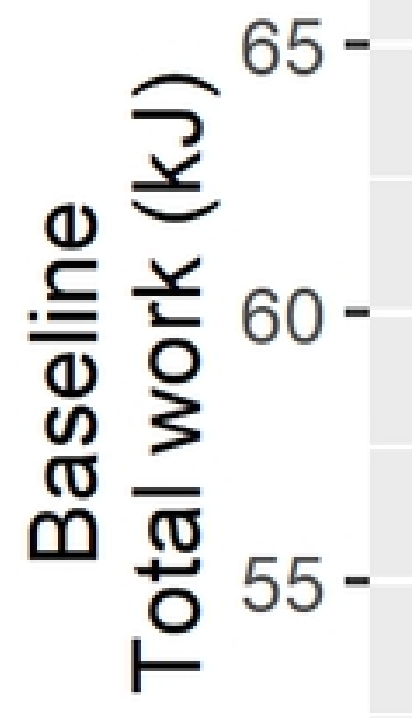

$50-$

45 -

$40-$

-

'́ $40 \quad 45 \quad 50$

55

6

65

70

75

Familiarisation

Total work (kJ)

Fig 1 
A $\quad \alpha=0.01$
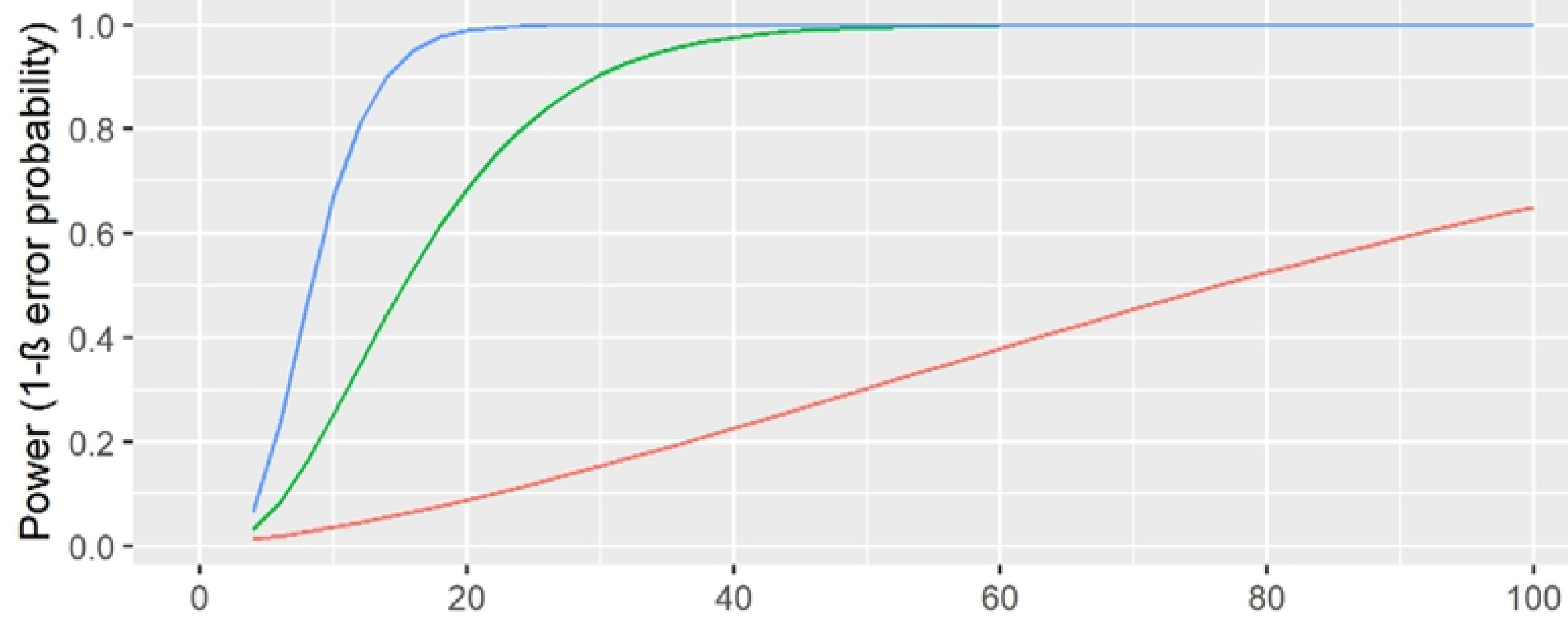

Sample size (n)

\section{B $\quad \alpha=0.05$}

bioRxiv preprint doi: https://doi.org/10.1101/2021.01.22.427755; this version posted January 22, 2021. The copyright holder for this
preprint (which was not certified by peer review) is the author/funder, who has granted bioRxiv a license to display the preprint in
perpetuity. It is made available under aCC-BY 4.0 International license.

3
0
0
0

0.8 -

은

2.6.

$0.4-$

$0.2-$

.

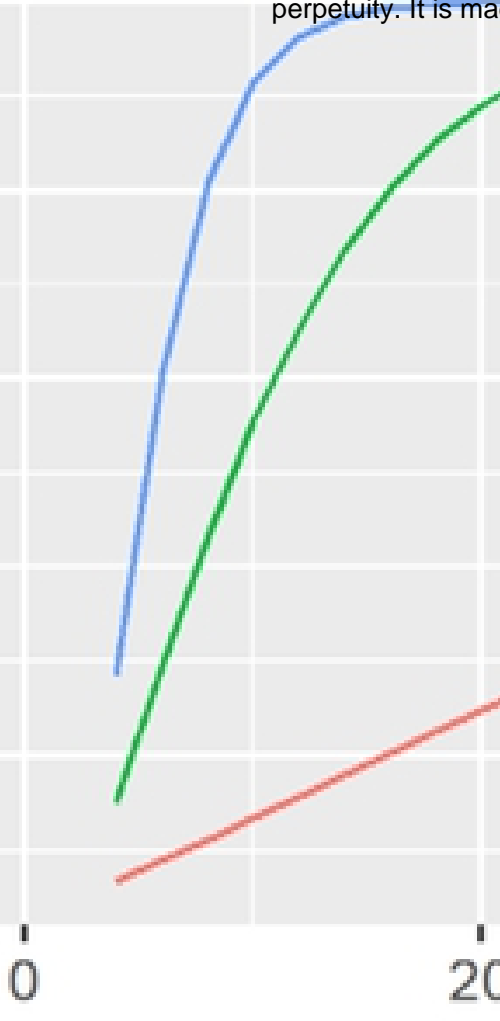

20

'ं'

60

80

100

Sample size (n)

$\alpha=0.1$
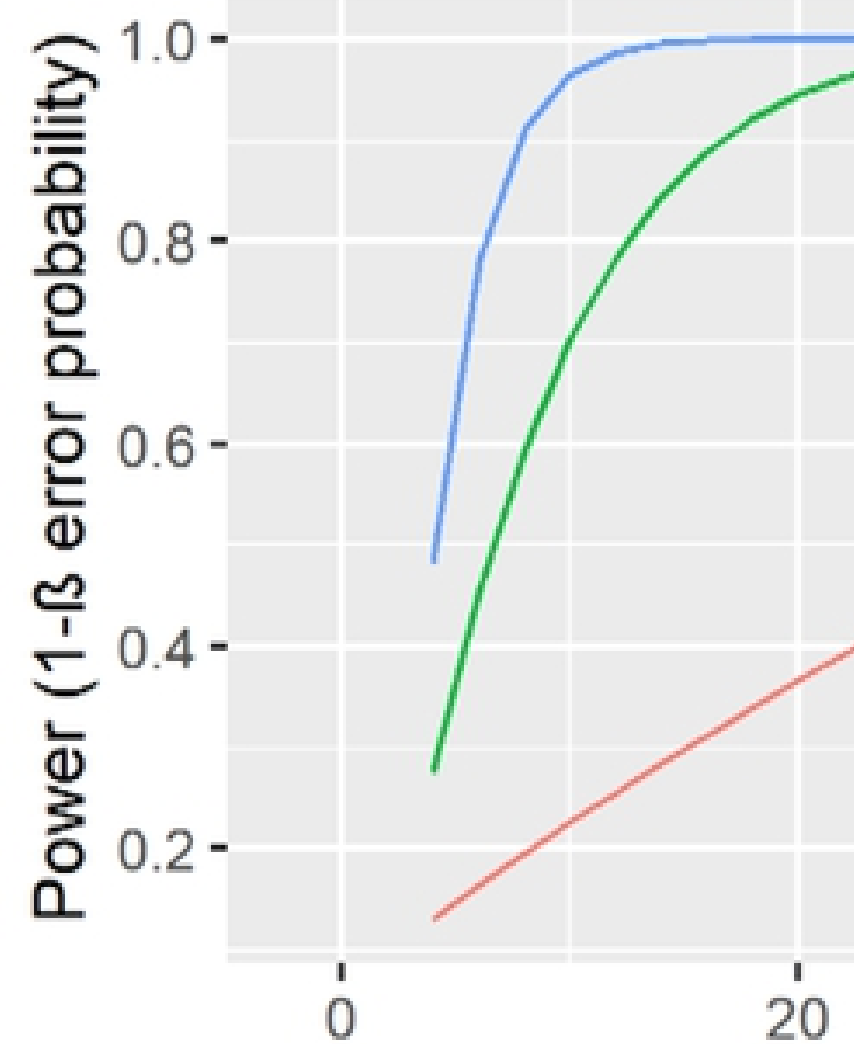

20

40

'́

80

100

Sample size (n)

Effect size (Cohen's $f$ )

Fig 2 


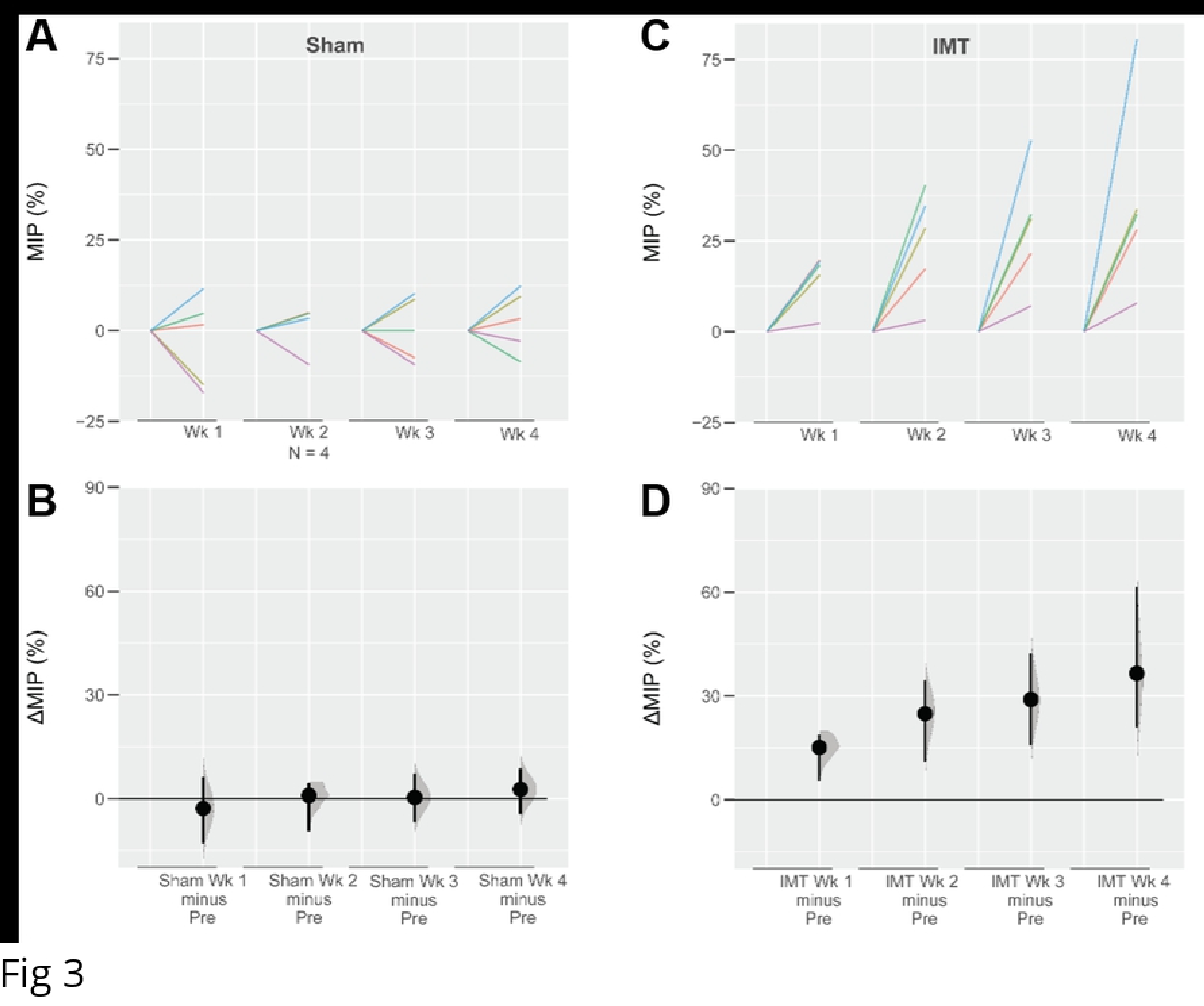


